\title{
OS PEDAGOGOS E O ENSINAR/APRENDER: IMPACTOS E DESAFIOS NA GESTÃO ESCOLAR
}

\author{
Carlos TOSCANO ${ }^{1}$ \\ Francismara Neves de OLIVEIRA ${ }^{2}$
}

RESUMO: Este trabalho tem como objetivo compreender os desafios envolvidos no ensinar e aprender no contexto da gestão escolar de programas voltados para o apoio à aprendizagem. Com base nas contribuições de Charlot (2000), Lahire (1997), Arroyo (2000), Bahia (2012) e Sawaia (2002) sobre o tema do aprender/não aprender na escola, construímos um roteiro de entrevista semiestruturado para atender ao objetivo proposto. A pesquisa, que se caracteriza por um estudo qualitativo, descritivo e interpretativo, conforme Cervo (2007) foi realizada em cinco escolas na cidade de Londrina - PR e envolveu oito pedagogos. Dentre os resultados obtidos, destacamos: a abertura da Sala de Apoio é considerada muito significativa para a aprendizagem e o desenvolvimento dos alunos que não têm o rendimento esperado. Tais alunos são usualmente identificados como portadores de dificuldades de aprendizagem, entretanto, por vezes, o desempenho insatisfatório é diagnosticado como resultante de problemas do ensino, formação insuficiente dos professores para a realidade atual, pouco envolvimento das famílias e falta de recursos. O programa provoca várias alterações no cotidiano escolar: rearranjo do espaço e novos materiais - e instaura a necessidade de novas formas de trabalho entre os agentes envolvidos sem que se tenham adequadas condições de realizá-las.

PALAVRAS-CHAVE: Ensinar e aprender. Sala de Apoio à Aprendizagem. Pedagogos. Significações.

\section{Introdução}

Na política educacional, não é recente o desenvolvimento de ações que se proponham equacionar questões relativas ao não aprender na escola. Com o intuito de situarmos brevemente esta problemática, destacamos algumas ações propostas por governos estaduais nas três últimas décadas.

Uma das propostas ocorreu em 1983, promovida pela Secretaria da Educação do governo do estado de São Paulo, marcando o início do período pós-ditadura, por meio

\footnotetext{
${ }^{1}$ Professor Associado do Departamento de Educação e do Programa de Pós-graduação em Educação. UEL - Universidade Estadual de Londrina. Londrina - PR - Brasil. 86057-970 - ctoscano@uel.br.

${ }^{2}$ Professor Associado. UEL - Universidade Estadual de Londrina. Londrina - PR - Brasil. 86057-970 francis.uel@gmail.com.
} 
de ações que visavam à democratização da escola, à participação dos docentes e à melhoria na qualidade educacional.

Dentre as ações, o processo de introdução do Ciclo Básico alterou o quadro de reprovação dos alunos ao final da então denominada primeira série, preocupação manifestada pela rede de ensino durante o período de levantamento dos problemas naquele momento. Seu objetivo era promover mudanças no processo educacional no início da escolarização. A grande marca desse projeto era ampliar o processo de alfabetização inicial das crianças para o período de dois anos, tornando as duas primeiras séries num ciclo contínuo (SÃO PAULO, 1984).

A implementação da proposta, entretanto, gerou desconfiança juntos aos professores da $1^{\mathrm{a}}$ série e certo deslocamento das reprovações para a $3^{\mathrm{a}}$ série.

Por meio de discussão de textos e reflexões acerca de práticas consideradas inovadoras em alfabetização, de cursos de capacitação de professores e de acompanhamento sistemático do trabalho dos capacitadores e dos professores, verificaram-se significativas mudanças na qualidade da produção escrita dos alunos.

Tal proposta constitui-se em um grande marco histórico, porque estava rompendo com a ineficácia das práticas anteriores, proporcionando uma relação mais efetiva entre professores e a Secretaria de Educação e melhoria na capacitação profissional tanto teórica como prática. Mas, Apesar dos esforços despendidos, continuou aumentando o índice de retenção só que, a partir de então, da segunda para a terceira série do Ensino Fundamental.

Como a questão do grande número de reprovações persistia, em 1996, foi criado o Projeto Classes de Aceleração, organizada pela Secretaria de Educação do Estado de São Paulo. Tal projeto teve como objetivo organizar a trajetória escolar dos alunos que possuíam defasagem entre idade/série. O aluno em defasagem era transferido da classe regular para uma classe de aceleração, como uma forma de recuperar o percurso escolar e proporcionar condições para superar suas dificuldades que produziram tal defasagem (SÃO PAULO, 1996).

Este Programa contou com a capacitação profissional dirigida aos professores, materiais pedagógicos e orientação pedagógica. Embora ocorresse a evasão de um grande número de alunos, a proposta foi considerada satisfatória, levando-se em conta os seguintes fatores: construção do projeto político pedagógico, material didático, capacitação profissional e acompanhamento do diretor e coordenador. Numa análise comparativa entre os alunos egressos e não egressos, observou-se que os dois tiveram 
um baixo desempenho, o que aponta a questão relativa à "má qualidade do ensino" (BAHIA, 2012).

Em 1997, foi criado pela Secretaria do Estado de São Paulo o Regime de Progressão Continuada, que teve como objetivo a diminuição dos índices de evasão e repetência, sendo organizado da seguinte maneira: o processo de escolarização deixa de ser seriado e passa a ser dividida em Ciclos: o Ciclo I - da primeira à quarta série - e Ciclo II - da quarta à oitava série. O sistema de avaliação final também sofreu transformações, na proposta seriada anterior, os alunos eram avaliados no término de cada ano letivo e, com esta nova proposta, eles acabavam sendo avaliados apenas no final do ano do último ciclo ( $4^{\mathrm{a}}$ e $8^{\mathrm{a}}$ séries). O processo de avaliação deveria ser permanente, com o objetivo de oferecer uma recuperação paralela (SÃO PAULO, 1997).

De acordo com a legislação que introduziu este sistema, o regime de progressão continuada deveria assegurar: avaliação institucional, avaliação da aprendizagem, atividades de reforço, possibilidades de adaptação, indicadores de desempenho, controle da frequência dos alunos, melhoria no ensino, avaliação do projeto, regimento adequado e a participação das famílias.

Portanto, a proposta teve o objetivo de elevar a autoestima do educando, assegurando sua permanência na escola, assim como sua aprendizagem/desenvolvimento, melhorando as relações sociais, estimulando suas potencialidades, garantindo um conhecimento sistematizado de qualidade $\mathrm{e}$ desempenhando uma ação favorável ao enfrentamento do fracasso escolar. Além disso, pedia mudanças nas condições de trabalho, já que o espaço físico era inadequado e a organização do trabalho não possibilitava uma efetiva relação entre os professores da sala regular e os da sala de recuperação.

$\mathrm{Na}$ implementação do Programa, os professores evidenciaram grandes dificuldades após a implantação desse projeto, posto requerer mudanças em suas práticas pedagógicas e de avaliação (inserção da avaliação com caráter diagnóstico do processo ensino-aprendizagem), bem como em termos de concepções teóricas, visto que era preciso saber diferenciar a progressão automática da progressão continuada.

Ao discutir tais problemas enfrentados pelo sistema educacional, Arroyo (2000) destaca que estamos à procura de soluções inovadoras para problemas muito antigos, porém sempre utilizando um novo método para "empurrar" o aluno na sua vida escolar e não se preocupando com seu processo de desenvolvimento. Portanto, as propostas 
devem ter como objetivo o desenvolvimento do educando, entendendo-o como um ser social e histórico, garantindo seu sucesso na aprendizagem, ou seja, tornar o aluno prioridade no processo de ensino e aprendizagem.

Em 2008, o governo do estado do Paraná propôs um Programa que também visava tratar da questão do não aprender, que levava à retenção dos alunos, denominado de Sala de Apoio à Aprendizagem. Na atualidade, por meio da Instrução n. 007/2011 SUED/SEED, as orientações que normatizam o programa foram redefinidas, indicando as diferentes responsabilidades de todos os agentes: direção e equipe pedagógica, professores da sala regular e professores da sala de apoio, dos núcleos regionais de ensino e da própria SEED.

De acordo com a referida Instrução, a abertura da Sala de Apoio é permitida para o ensino das disciplinas de Língua Portuguesa e Matemática, no $6^{\circ} / 9^{\circ}$ ano do ensino fundamental. Seu funcionamento deve ocorrer no contraturno escolar como atividades complementares. A carga horária para cada disciplina deve ser de quatro horas aulas semanais e as salas devem conter no máximo 20 alunos. O professor da sala regular deve indicar os alunos para a sala de apoio de acordo com suas necessidades educacionais, por intermédio de uma avaliação diagnóstica. Executar um plano de trabalho de acordo com as especificidades de cada aluno e a sua participação integral. Os professores regentes da sala regular devem acompanhar o desempenho dos seus alunos, possibilitar a superação das dificuldades e, junto com os demais profissionais, analisar se o aluno permanece ou se é liberado das atividades da sala de apoio (PARANÁ, 2011).

Os professores da sala de apoio devem ter um plano de trabalho definido. Organizar pastas para cada aluno referente ao seu desempenho, sendo acessível a todos os profissionais envolvidos no processo pedagógico. A decisão de dispensa ou permanência do aluno na Sala de Apoio deve ser realizada em conjunto com o Conselho de Classe. O Programa prevê a realização de capacitação profissional promovida pela Secretaria Estadual de Educação em conjunto com os Núcleos Regionais de Ensino. Foram definidos os seguintes objetivos para cada uma das séries abrangidas pelo Programa:

Elaborar o Plano de Trabalho Docente juntamente com a Equipe Pedagógica, Professores Regentes, de acordo com o disposto no Projeto Político Pedagógico para Língua Portuguesa e Matemática, adequados à superação das dificuldades pertinentes a cada série, como 
segue: i) $5^{\text {a }}$ Série $/ 6^{\circ}$ Ano: oralidade, leitura, escrita. Formas espaciais e quantidades nas suas operações básicas e elementares, dos Anos Iniciais do Ensino Fundamental. ii) $8^{\text {a }}$ Série $/ 9^{\circ}$ Ano: oralidade, leitura, escrita. Reconhecer as características e propriedades dos triângulos e quadriláteros; porcentagem; leitura, construção e interpretação de tabelas e gráficos; identificar e reconhecer números nas suas diversas representações; operações com números; cálculo de perímetro e área de polígonos; cálculo de conversão de medidas (tempo, temperatura, comprimento e capacidade); noções de função afim e quadrática. (PARANÁ, 2011).

De acordo com a referida Instrução, o núcleo regional de ensino deverá disponibilizar a cada escola a legislação específica do Programa Salas de Apoio à Aprendizagem, promover encontros com os professores, diretores e a equipe pedagógica para explicar qual o objetivo da Sala de Apoio, seguindo com orientações gerais.

A SEED/DEB/Coordenação da Educação Integral se responsabiliza por acompanhar a implantação do Projeto, fornecer materiais pedagógicos e promover a capacitação profissional e/ou formação continuada.

No que concerne aos diretores e equipes pedagógicas, o Programa define as seguintes atribuições:

a) Apresentar e discutir a legislação específica do Programa Salas de Apoio à Aprendizagem com o coletivo da escola.

b) Decidir, com os professores regentes, sobre a indicação dos alunos para composição das turmas, de acordo com diagnóstico realizado.

c) Orientar sobre a elaboração do Plano de Trabalho Docente para as Salas de Apoio à Aprendizagem, acompanhando sua efetivação e propondo metodologias adequadas às necessidades dos alunos, diferenciando-as das atividades da classe comum.

d) Orientar as famílias a respeito do Programa Salas de Apoio à Aprendizagem, informando aos pais ou responsáveis sobre a necessidade e importância dos alunos estenderem seu tempo escolar.

e) Garantir a participação dos professores das Salas de Apoio à Aprendizagem no Conselho de Classe ou, na ausência desses professores, apresentar as questões relativas à aprendizagem dos alunos.

f) Acompanhar os alunos, buscando sua participação integral no Programa, mantendo pais ou responsáveis informados quanto à frequência, aproveitamento nas Salas de Apoio à Aprendizagem e na classe comum.

g) Organizar as questões estruturais, tais como espaço físico apropriado, alimentação, acesso a materiais didáticos, garantindo a frequência dos alunos e o funcionamento das salas.

h) Orientar os Professores no preenchimento dos relatórios das Salas de Apoio à Aprendizagem.

i) Acompanhar a frequência e a movimentação dos alunos matriculados nas Salas de Apoio à Aprendizagem e providenciar a 
substituição quando da superação das dificuldades apresentadas, oportunizando o atendimento de novos alunos.

j) Organizar o acompanhamento das Salas de Apoio à Aprendizagem em escolas com dualidade administrativa, garantindo seu funcionamento no contraturno.

k) Encaminhar as solicitações de constituição de Salas de Apoio à Aprendizagem das instituições, de acordo com o disposto nos itens "I" "3" e "I" "4", ao Núcleo Regional de Educação para Parecer e envio ao Departamento de Educação Básica. (PARANÁ, 2011).

Portanto, assim como os outros programas, a criação da Sala de Apoio tem como finalidade resolver problemas relativos ao ensinar/aprender. Ao oferecer aulas no contraturno em duas áreas do conhecimento entendidas como básicas, tenta sanar as defasagens de aprendizagem que os alunos apresentam, consideradas imprescindíveis para avançar na apropriação do conhecimento e como forma de evitar o fracasso escolar ou mesmo a evasão escolar.

\section{Referencial teórico e metodológico da pesquisa}

O presente estudo é tributário dos estudos de Lahire (1997) e Charlot (2000), particularmente nas obras em que o sucesso e o fracasso escolar foram temas tratados por eles. Como sociólogos e pesquisadores do campo da educação, consideramos que as análises que ambos realizaram contribuem para ampliar o olhar sobre os temas aqui referidos, além de compartilharem aspectos comuns no que diz respeito à concepção do sujeito, em cuja base nós observamos algumas aproximações com a perspectiva histórico-cultural.

Em Charlot (2000), encontramos a problematização da própria concepção de fracasso escolar que circula no e para além do espaço escolar. Este autor considera que o fracasso escolar não é um "fato" que a "experiência" permite constatar, mas uma forma de expressar uma interpretação de acontecimentos relacionados a uma situação particular. Em suas palavras: “o 'fracasso escolar' não existe; o que existe são alunos em situação de fracasso" ou "histórias escolares que terminaram mal" (CHARLOT, 2000, p.16). Ainda de acordo com o autor: "O fracasso escolar não é um monstro escondido no fundo das escolas e que se joga sobre as crianças mais frágeis, um monstro que a pesquisa deveria desemboscar, domesticar, abater" (CHARLOT, 2000, p.16). 
Para quem intenciona compreender tais situações, ele propõe que se ouçam as histórias de quem viveu a experiência de resultados ruins, dificuldades em certas situações ou orientações, sejam estudadas as situações que se apresentaram difíceis para certos alunos em algum momento de sua trajetória escolar. É fundamental ainda que se escutem as significações elaboradas com base nessas experiências: se "ele constrói uma imagem desvalorizada de si, ou, ao contrário, consegue acalmar esse sofrimento narcísico que é o fracasso" (CHARLOT, 2000, p.17-18).

Ao considerar o sujeito, Charlot (2000, p.53) se fundamenta por uma posição antropológica, pela qual o homem nasce inconcluso e entra em um mundo em funcionamento, o mundo humano, no qual, para fazer parte deste, é preciso aprender.

Nascer é penetrar nessa condição humana. Entrar em uma história, a história singular de um sujeito inscrita na história maior da espécie humana. Entrar em um conjunto de relações e interações com outros homens. Entrar em um mundo onde ocupa um lugar (inclusive, social) e onde será necessário exercer uma atividade.

É nesse contexto mais amplo que ele situa as diferentes figuras do aprender e a necessária mobilização do sujeito para que o aprendizado ocorra.

Para Lahire (1997), há uma pluralidade de situações reais que envolvem tanto "fracasso escolar" como o "sucesso escolar", inclusive nas camadas populares, mas não somente nelas. Esta diversidade e abrangência coloca um problema para os que tomam como homogêneo os universos sociais, levando em conta apenas as posições econômicas ocupadas pelos sujeitos na sociedade. De acordo com ele,

Só podemos compreender os resultados e os comportamentos da criança se reconstituirmos a rede de interdependências familiares através da qual ela constituiu seus esquemas de percepção, de julgamento, de avaliação, e a maneira pela qual estes esquemas podem reagir quando funcionam em formas escolares de relações sociais. (LAHIRE, 1997, p.19, grifo do autor).

Nesta perspectiva, para compreender as diferenças "secundárias" entre famílias populares cujos níveis de renda e escolar eram bastante próximos, formulou um conjunto de questões que nortearam suas reflexões sobre a diversidade de situações que a realidade apresenta e suas correlações com o aprendizado escolar. Ao questionar as referências que a própria sociologia toma, como, por exemplo, as semelhanças por suas 
condições econômicas e culturais - consideradas de forma grosseira a partir da profissão do chefe da família -, ele pergunta:

Como é possível que configurações familiares engendrem, socialmente, crianças com níveis de adaptação escolar tão diferente? Quais as diferenças internas nos meios populares suscetíveis de justificar variações, às vezes consideráveis, na escolaridade das crianças? O que pode esclarecer o fato de uma parte delas, que tem probabilidade muito grande de repetir o ano do curso primário (anos iniciais do ensino fundamental), consegue escapar desse risco e até mesmo, em certos casos, ocupar os melhores lugares nas classificações escolares? (LAHIRE, 1997, p.12).

Segundo ele, a personalidade da criança, seus "raciocínios" são incompreensíveis fora das relações sociais em que são tecidas, inicialmente no âmbito da família, mas em um universo de objetos ligados às formas de relações sociais intrafamiliares.

\begin{abstract}
A criança constitui seus esquemas comportamentais, cognitivos e de avaliação através das formas que assumem as relações de interdependência com as pessoas que a cercam com mais frequência e por mais tempo. Ela não "reproduz", necessariamente e de maneira direta, as formas de agir de sua família, mas encontra na sua própria modalidade de comportamento em função da configuração das relações de interdependência no seio da qual está inserida. Suas ações são reações que "se apóiam" relacionalmente nas ações dos adultos que, sem sabê-lo, desenham, traçam espaços de comportamento e de representações possíveis para ela. (LAHIRE, 1997, p.17).
\end{abstract}

Ao problematizar o que ele considera como “[...] a tendência a reificar os comportamentos das crianças como traços de caráter ou de personalidade", este autor considera que tais traços não aparecem em um vazio de relações sociais. Ao contrário, afirma que os mesmos são "[...] o produto de uma socialização passada e também da forma das relações sociais através dos quais esses traços se atualizam, são mobilizados" (LAHIRE, 1997, p.18).

Lahire (1997) chama nossa atenção para a necessidade de se levar em conta a questão da interdependência de variados fatores localizados em diferentes espaços e tempos. Por conta disso, em vez de privilegiar um ou outro aspecto da socialização familiar e/ou de estabelecer correlações fator por fator, opta em descrever e analisar as “configurações singulares”, entendidas como combinações específicas de traços gerais. 
Sob os aportes destas breves referências, procuramos compreender os desafios enfrentados pelos gestores locais, geralmente pedagogos e/ou diretores, encarregados de implantar e supervisionar o funcionamento do Programa Sala de Apoio à Aprendizagem, do governo do Paraná, em suas respectivas unidades escolares.

Tal estudo, de caráter qualitativo, descritivo e interpretativo, de acordo com Cervo (2007), analisa as significações dos sujeitos acima referidos diante dos desafios que o não aprender coloca para os profissionais na escola.

A pesquisa, aprovada pelo comitê de ética em pesquisa envolvendo seres humanos da universidade estadual local, foi realizada ao longo do ano de $2012 \mathrm{em}$ cinco escolas e contou com a participação de oito pedagogos e um diretor. Teve como objetivo compreender os desafios que se apresentam à implementação do referido Programa. Inicialmente, foi feito um levantamento das escolas estaduais que participavam do Programa da Sala de Apoio à Aprendizagem na cidade de Londrina, Paraná. Os dados, apresentados no próximo item, foram colhidos por meio de entrevistas realizadas, orientadas por um roteiro semiestruturado.

Neste texto, os entrevistados serão identificados conforme o lugar social ocupado na estrutura escolar: os pedagogos responsáveis pelo Programa nas escolas em que atuavam foram nomeados por $P 1, P 2, P 3, P 4, P 5, P 6, P 7, P 8$, doravante referidos como gestores locais.

\section{Resultados e discussão}

Essa pesquisa, conforme Cervo (2007), se caracteriza como um estudo descritivo, qualitativo e interpretativo que tomou por base os dizeres de seus sujeitos a partir de questões propostas que colocavam em foco um contexto específico. Assim, com vistas a investigar o processo de instalação da Sala de Apoio à aprendizagem no ano de 2012, iniciamos a pesquisa perguntando como foi em cada uma das escolas a sua constituição. De acordo com as respostas, nem todos os sujeitos tiveram possibilidade de elucidar como se deu sua instalação, uma vez que alguns deles estavam chegando à escola naquele momento, caso de P3 e P8, e, desse modo, não tinham participado do processo, por isto, suas respostas procuraram resgatar a vivência de anos anteriores ou tomaram por base as instruções genéricas previstas no próprio Programa. Um aspecto ressaltado diz respeito ao levantamento dos alunos que evidenciavam dificuldades. Esse parece ser o elemento desencadeador do processo de instalação e funcionamento e, 
nesse sentido, algumas escolas iniciam o diagnóstico já no início do ano letivo. Afirma P3:

Olha, desde o começo do ano, foram selecionados os alunos, foi feito uma avaliação, os professores fazem uma avaliação dos alunos, aí detecta o aluno que tem aquela dificuldade em produção de texto, com base nesses dados, eles são encaminhados pra sala de apoio.

Observamos que outras características contribuem para marcar o processo, como

"IDEB baixo", "escola de risco", conforme apontado por P1, e, neste sentido, elas, por assim dizer, já "antecipariam" a ocorrência das dificuldades de aprendizagem de parte de seus alunos. Tais características, conforme analisado em diferentes perspectivas por Aquino (1997), Patto (1990), Lahire (1997), Charlot (2000) e Sawaia (2002), estão ainda muito presente no cotidiano escolar e denotam a forma como lidar com tais aspectos da realidade, os quais vão marcando os modos como os indivíduos se referem e atuam em contextos sociais marcados pela desigualdade e discriminação social. Cabe destacar que são tomados como fato em si, como "propriedades" ou "traços de caráter ou de personalidade", conforme expressão de Lahire (1997, p.17), marcas que essa desigualdade e essa discriminação produziram nos indivíduos.

Outros pedagogos, entretanto, indicaram que o elemento desencadeador do processo de constituição da Sala de Apoio foi a "avaliação diagnóstica", realizada pelos professores da sala regular. Explica P8:

Os professores da sala, no início do ano, fizeram uma avaliação diagnóstica, detectaram aqueles alunos que têm defasagem em conteúdos básicos. Eles preencheram a ficha e, a partir dessa ficha, a gente solicitou que a família comparecesse aqui pra assinar esse termo de compromisso que o aluno vem participar.

Ainda no que tange às questões relativas às condições de funcionamento do Programa, indagamos se as escolas receberam recursos físicos e/ou financeiros e em que foi utilizado. Com esta questão, queríamos saber se houve alocação específica de recursos para essa finalidade.

Não, que eu saiba não. Só o pagamento dos professores (P2).

$\mathrm{O}$ financeiro eu não sei, eu não sei te responder, aí eu teria que me informar melhor (P3).

Não, nenhum. Tem que ter disponível para fazer o pedido no começo do ano, mas, depois, não recebemos nada. Precisamos ter salas 
disponíveis. O aluno não é contado a mais também, é um aluno que vem ele come a merenda, o professor utiliza os materiais da escola, mas ele não conta duas vezes para recebermos a verba $(\mathrm{P} 4)$.

De acordo com as respostas obtidas, parece que ou não houve envio de recursos específicos ou os pedagogos entenderam que o enviado não diz respeito à especificidade do Programa, que os mesmos fazem parte de recursos gerais recebidos pela escola. Nesse sentido, fica apontada uma falta de esclarecimento sobre os mecanismos que orientam os financiamentos cobertos pelo referido Programa e suas formas de execução. Percebe-se também que a autorização do funcionamento da Sala de Apoio requer contrapartida da escola: certo número de alunos dentro do estabelecido pelo Programa e um lugar específico para o seu funcionamento, produzindo uma pressão a mais sobre o conjunto das demais demandas que a escola tem que lidar no seu cotidiano, cujo encaminhamento irá ser decisivo para que a oferta seja possibilitada em cada uma das unidades escolares que identificaram a necessidade de abertura da Sala de Apoio.

Com relação aos critérios utilizados para o levantamento dos alunos indicados para participarem do Programa e, dessa forma, serem indicados a frequentar a Sala de Apoio, os depoimentos dos gestores locais permitiu-nos constatar que esta tarefa recai sobre os professores de Língua Portuguesa e Matemática, em conformidade com o previsto. Os critérios, consequentemente, são definidos por esses profissionais a partir dos diagnósticos que eles realizam.

\footnotetext{
Os professores das disciplinas de Português e Matemática que preenchem uma ficha, um roteiro de avaliação diagnóstica, que eles colocam quais são as maiores dificuldades, que os alunos têm em relação ao conteúdo, tanto da disciplina mesmo, do ano, quanto de conteúdos de conceitos básicos (P1).

Os alunos que apresentam índice de defasagem, de falta de prérequisitos, daí esses alunos são encaminhados (P4).

Os professores da sala regular, do horário normal. Eles fazem uma prova diagnóstica, uma avaliação diagnóstica, na verdade, não necessariamente prova, mas algum tipo de avaliação e detectam a dificuldade do aluno e esses alunos são encaminhados (P5).
}

De acordo com o exposto, verificamos que os modos pelos quais os alunos são indicados apresentam certa variação em torno da nota, indicador de uma possível e/ou provável reprovação nestas duas áreas de conhecimento eleitas pelo Programa.

Investigamos ainda como os gestores locais veem a questão da escolha de Língua e Portuguesa e Matemática ante o conjunto das demais áreas de conhecimento 
que são objeto de ensino e aprendizagem presentes no currículo dos anos finais do ensino fundamental, etapa da escolaridade focalizada pelo referido Programa. No conjunto das respostas obtidas, constatamos uma variedade de posicionamentos. P3 afirmou não saber responder, porque "já peguei o bonde andando", mas acredita que deveria ser para todas as disciplinas. Essa posição é compartilhada por D, P2, P6. Dentre os nossos sujeitos, P8 e P7 concordam com a ênfase ao Programa de Língua Portuguesa e Matemática, por compreenderem que elas são básicas.

Eu concordo porque eu acho que elas são a base de tudo. Como eu disse: a questão da interpretação, o aluno que não lê não vai escrever bem, então tem que ser português e matemática mesmo, e, em matemática, a gente está com problema numa turma de ensino médio e o professor é..., acredita que as notas baixas dos alunos são porque eles não sabem fazer cálculo e ele não deixa usar calculadora. Então você vê que, realmente, a matemática e o português são disciplinas que de base mesmo e que vão influenciar todas as outras. Não que eu acho que se tivesse, vamos supor, um apoio de história, geografia, de ciências não fosse importante, mas como tenho que pegar aquilo que é básico, mais importante, eu acho que dentro das disciplinas vai ser português e matemática mesmo $(\mathrm{P} 8)$.

Uma vez que, nas orientações oficiais emanadas da política educacional, ganhou força e sustentação que o ler, escrever e contar constitui a "base de tudo", observamos que, no espaço escolar, os seus agentes, de uma forma geral, não problematizam mais esta perspectiva. Pelas respostas obtidas, parece que a produção deste "senso comum escolar" tem como premissa que tais habilidades teriam um valor em si mesmo e, nesse sentido, não careceriam de especificação ou elucidação. Como consequência do processo de uma pretensa naturalização dessa compreensão, ficam, aparentemente, descartadas questões sobre o sentido do que se pede na leitura, na escrita e no contar, conforme discutido, dentre outros, por Hébrard (2000) quando analisa os problemas envolvidos no processo inicial da leitura e escrita; Soares (2011) ao abordar as diferentes perspectivas do ensino da Língua Portuguesa e Schiemann, Nunes e Carraher (2012) quando discutem as formas de conhecimento e aprendizado da Matemática na escola e na vida.

Somente P1 faz uma consideração acerca da forma do trabalho em sala de aula que poderia repercutir, inclusive, no próprio diagnóstico da dificuldade de aprendizagem: 
Se você trabalhar Português e Matemática de uma maneira interdisciplinar, não precisaria ter uma Sala de Apoio pra cada disciplina, porque você pode trabalhar um texto de História, de Sociologia, de Filosofia na área de Língua Portuguesa. Do mesmo jeito que você, pra dar Matemática, pode também contextualizar o problema, não é? O autor que você está trabalhando de certa equação e tal, então se fosse trabalhar de uma maneira interdisciplinar, uma sala de Português..., de apoio não é? Uma Sala de Apoio de Português e Matemática seriam suficientes, porém não é isso que eu acho que acontece, eu acho que eles focam muito assim, em "probleminhas pontuais", dessas áreas. Não faz uma coisa mais ampla. Até porque, como tem baixa frequência nessas duas turmas, se tivesse uma Sala de Apoio pra cada disciplina eu acho que não solucionaria os problemas. O que eu acho que deveria ter é ampliar pra todas as turmas, pra não ser só o sexto e o nono ano, tinha que ter pro sexto, pro sétimo, por que, às vezes, o aluno frequentou um pouco no sexto, e passou pro sétimo, e aí no sétimo ele não tem mais! E ele tá com dificuldade ainda. É aquilo que eu falei, não tem dificuldade às vezes do conteúdo em si dali, ele não tá entendendo aquele conteúdo do sétimo ano, porque não foi construído com ele anteriormente..., sabe?...Tem aluno que não sabe ler direito no nono ano! Só que eu não preciso trabalhar só poema, conto e lenda pra ele aprender a ler, não é? Eu posso trabalhar uma reportagem de um jornal, fazer uma articulação com as outras disciplinas, só que isso também é um pouco difícil porque os professores são da área de Português e Matemática, então, às vezes, seria interessante..., não sei..., ter uma capacitação com esses professores, sabe?... Primeiro, pra ele, não é?Falar pra perguntar que tipo de texto que eles vão selecionar, que tipo de problema, e também, eu acho que o que é demais importante na Sala de Apoio, é como você tem um número menor de alunos, é fazer coisas diferentes, porque o que eles já veem na sala de aula, eles já não conseguiram aprender daquele jeito, então, eu acho que na Sala de Apoio você tem que ter uma intervenção diferenciada, não adianta você querer fazer a mesma coisa que você faz em uma sala de aula regular, porque o aluno já não entendeu daquele jeito, então tem que fazer coisas mais concretas porque, se aquele aluno não está conseguindo entender uma multiplicação ali no quadro, você (o professor) vai ter que trazer um concreto pra ele (o aluno), não é?

P1, neste momento, redimensiona o trabalho pedagógico escolar não só do professor da sala regular como o da Sala de Apoio, que são profissionais com enfoques diferentes, mas que ensinam para os mesmos alunos. Destaca a importância de contextualizar o que se busca ensinar e a necessidade do cuidado com os materiais que se apresentam nas atividades de ensino. Nesse sentido, coloca, no centro da discussão, a necessária competência técnica do profissional da educação escolar.

De certa forma, explica com outros termos o que Charlot (2011, p.24) afirma ao responder uma questão sobre a formação docente, destacando que esta se assenta em dois pilares: 
O primeiro pilar é a formação técnica, profissional, um saber como ensinar. Se não tem competência profissional, o professor não consegue ensinar bem. A aula fica chata e o aluno não gosta de aprender. [O segundo pilar] é o trabalho pedagógico, políticopedagógico, a ser feito junto com o trabalho profissional.

Com relação às contribuições que a escola efetivamente recebe para realizar o

trabalho na Sala de Apoio, foram destacados aspectos que estão previstos no Programa em análise, como a vinda de professores especialmente contratados para este trabalho, o curso de capacitação dos professores que vão participar do Programa realizado em Curitiba, reuniões promovidas no núcleo de ensino.

Eu sei que, no começo do ano, tem um curso da prefeitura que são para os professores da Sala de Apoio. Nem todos participam porque o curso é lá em Curitiba. Eles oferecem esse curso, o núcleo oferece. Eu já participei quando eu tava na coordenação em 2009, eles fizeram um curso em Curitiba, foi muito gratificante, a gente aprende muita coisa, muitos professores vão. Trocas de experiência mesmo. Eles passam todo material, passam como funciona. Aí, por exemplo, se na minha escola poderiam ter ido três, mas só eu que pude ir, aí eu chego e passo para os meus colegas de trabalho (P7).

Pela resposta do diretor, foi possível observarmos o desafio que se coloca aos gestores locais em manter o Programa em funcionamento, isto é, manter a Sala de Apoio aberta com a presença do número mínimo de alunos. Dentre os desafios enfrentados no dia a dia para seu funcionamento, os gestores locais relataram questões como a dificuldade de o aluno retornar à escola no contraturno para participar das atividades de apoio à aprendizagem.

O fato de o curso de capacitação ser em Curitiba também foi apontado como uma dificuldade, visto que, por vezes, inviabiliza a ida do professor que está distante deste local.

Então, quer dizer, eles te oferecem sim, mas infelizmente esse curso, ainda, é oferecido em Curitiba e muitas vezes pra gente se descolar de Londrina pra Curitiba é difícil. Então, até na última palestra que teve, há possibilidade que, em 2013, comece a ser feito aqui em Londrina esse curso. Aí podendo participar mais professores, mais pedagogos, mais professores que até estão interessados em pegar essas salas de apoio não é? (P7).

O núcleo só paga a carga horária dos professores, nada mais, o restante é com a gente. No começo, tivemos até um problema com a 
merenda, porque muitos alunos vêm cedo e já fica pra aula à tarde, então precisam almoçar aqui, agora deu certo, a merendeira se prontificou a fazer o almoço. Porque a maioria mora longe da escola e precisa ficar e comer por aqui, às vezes, o aluno só precisa de matemática, mas acaba ficando na de português também, porque não tem onde ficar, ele acaba assistindo as duas matérias mesmo precisando somente de uma, a aula acaba às $10 \mathrm{~h}$ e onde esse aluno vai ficar nós não temos espaço para isso aqui na escola, não tem ninguém pra cuidar deles no pátio, não é igual às escolas dos Estados Unidos que têm sala de convivência, armário, um lugar para eles descansarem. Então essa foi a alternativa que encontramos. Ontem mesmo, a professora de Português veio reclamar que está com 25 alunos e ela não está conseguindo fazer o trabalho diferenciado que é proposto, ela está dando aula pro $6^{\circ}$ ano de manhã e à tarde (P2).

Ao observar as dificuldades encontradas no cotidiano escolar, P2 faz menção a uma questão extremamente importante e geralmente pouco mencionada: a infraestrutura escolar que usualmente já não é satisfatória para a realização das questões ordinárias do funcionamento escolar e, com esta nova proposta, vê-se diante de novas necessidades, cujo equacionamento não está, por vezes, ao alcance daqueles que têm que lidar com tais situações. P2 acrescenta outro aspecto quando trata do problema do excesso de alunos, provocando, por assim dizer, uma descaracterização do trabalho com vistas à recuperação dos alunos: turma pequena como condição para um processo de ensino diferenciado.

Ao perguntarmos aos gestores locais como eles se sentem coordenando este trabalho na escola onde atuavam, suas respostas evidenciaram uma relativa satisfação com o Programa e os resultados obtidos e uma sensação de angústia quanto a algumas dificuldades/limitações com que se deparam no processo de execução do Programa.

Eu estou gostando tá, porque eu entrei esse ano aqui nessa escola; no começo; nós tínhamos outra pedagoga que ficava mais responsável pelos alunos dos sextos anos à tarde, é..., inclusive o núcleo veio na nossa escola esse ano, eu conversei com o pessoal do núcleo e disse que era novo pra mim, agora que estou fazendo um acompanhamento mais de perto e, assim..., além da dificuldade que eu gosto, mas ao mesmo tempo eu sinto que, às vezes, não caminha assim do jeito que eu gostaria (P3).

Olha, depende, tem épocas que é muito legal e tem épocas que eu me sinto muito frustrada, porque eu não consigo acompanhar no dia a dia como acontece, entendeu. Não tem tempo pra isso. Somos poucas pedagogas, então assim, eu acabo tendo que socorrer outros problemas da escola e não me dedicar pra isso, então eu acabo deixando muito a desejar o meu trabalho, porque eu não tenho tempo pra fazer (P5).

Eu sinto assim que a equipe pedagógica tem um papel muito importante, porque é ela que faz mediação desse trabalho, inclusive 
quanto à frequência desses alunos. Porque o professor da Sala de Apoio ele só vai passar "fulano não veio" e eu vou ter que buscar esses alunos e ver como ele está fazendo. Eu acho que a gente tem um papel muito importante, mas que a gente não consegue que seja bem feito, entendeu? (P8).

A gente tem muita dificuldade em trazer os alunos, porque a gente vai atrás da família, vai atrás dos responsáveis, e tem aqui na comunidade..., é..., não tem essa cultura de participação na escola, então é muito pouca participação, não só na Sala de Apoio como nos outros projetos (P1).

Observamos, com base em seus depoimentos, que esses profissionais percebem o papel social do referido Programa no seu cotidiano e, para realizar o seu trabalho, fazem diferentes "usos de si”, expressão cunhada por Schwartz (2000), com vistas a lidar com os desafios e obstáculos que a realidade lhes apresenta. Entretanto, pelo fato de se tratar de um trabalho real, cuja ação se faz de forma interdependente com a de outros atores em condições concretas de existência e de possibilidades, os resultados obtidos são percebidos, com frequência, como aquém do pretendido ou imaginado/idealizado.

\section{Comentários Finais}

Pensar, conceber, por no papel um programa no campo da educação escolar é uma tarefa complexa, por exigir análise do problema a ser enfrentado em sua gênese. Como fenômeno social, o "problema" do não aprender na escola tem raízes históricas, sociais e culturais e, por esta múltipla dimensão, o seu diagnóstico e busca de sua superação não se apresenta como uma tarefa fácil e nem imediata. Além disso, por vezes, o simplismo e o imediatismo, na obtenção de resultados no curto prazo, ignoram fatores que se inter-relacionam e que se localizam em diferentes espaços e tempos.

Nesse sentido, Charlot (2000, p.14), em sua análise sobre a questão do fracasso escolar, convida-nos a refletir sobre a complexidade envolvida quando afirma:

A questão do fracasso escolar remete para muitos debates: sobre o aprendizado, obviamente, mas também sobre a eficácia dos docentes, sobre o serviço público, sobre a igualdade de "chances", sobre os recursos que o país deve investir em seu sistema educativo, sobre a "crise", sobre os modos de vida e o trabalho na sociedade de amanhã, sobre as formas de cidadania, etc. 
No caso do referido Programa aqui analisado e valendo-nos do olhar dos gestores locais, observamos que as tentativas de por um programa desse porte em funcionamento tem provocado várias alterações na realidade local das escolas, as quais vão desde o estabelecimento de novas demandas ao trabalho docente e à gestão escolar até a requererem um redimensionamento na infraestrutura física e nos recursos humanos disponíveis, materiais pedagógicos que possam subsidiar o trabalho docente, como certa reorganização no funcionamento cotidiano da unidade escolar.

Além disso, o funcionamento do Programa requer dos responsáveis pelos alunos uma nova exigência que implica na necessidade de reorganização nos diferentes arranjos dos familiares ou dos responsáveis pelos alunos para que os mesmos possam participar das atividades do contraturno, sem contar, é claro, o aumento dos custos envolvidos nessa participação.

Outro aspecto-chave previsto para que o Programa atinja os objetivos pretendidos diz respeito à articulação entre os diferentes protagonistas que nele atuam, ocupando distintos lugares sociais: cabe ao pedagogo ou mesmo ao diretor, conforme a realidade de cada escola, a responsabilidade de instalar o Programa em sua unidade, fazendo cumprir todas as exigências para que seja possível obter a autorização para a abertura da Sala de Apoio e garantir a permanência dessas condições para que seu funcionamento não tenha descontinuidade. Cabe ainda ao gestor local o papel de articulador entre os diferentes profissionais envolvidos: o professor da sala regular, que vai diagnosticar e indicar os alunos que requerem o apoio, e o professor da Sala de Apoio propriamente dito, que vai planejar as atividades a partir do diagnóstico realizado. Cabe ainda a esses profissionais entrar em contato com os responsáveis pelos alunos que precisam ser informados, orientados e, por assim dizer, ajudados para que possam contribuir nesse processo.

Tendo em vista que, na maioria dos casos, os professores da sala regular e da Sala de Apoio, por força da organização de suas atividades profissionais, não têm possibilidade de contato pessoal direto e regular, porque atuam em várias escolas, muitas vezes, é ao pedagogo que fica atribuída a tarefa de buscar as informações junto aos professores. Em consequência, fica comprometida a necessária comunicação para o desenvolvimento adequado do trabalho de recuperação dos alunos envolvidos.

Desse modo, destacam-se desafios interpostos ao trabalho real para por em funcionamento uma proposta de programa educacional com vistas ao apoio à 
aprendizagem escolar de alunos do ensino fundamental. Conforme destaca Clot (2007, p.14):

O trabalho não é só organizado pelos projetistas, pelas diretrizes e pelo enquadramento. Ele é organizado por aqueles e aquelas que o realizam, e essa organização coletiva comporta prescrições indispensáveis à feitura do trabalho real.

Apesar das tentativas desenvolvidas por tais profissionais e do esforço dos responsáveis pelos alunos envolvidos, nem sempre o resultado obtido é o almejado. A indicação do sentimento de angústia que se depreende, pelos dados obtidos junto aos gestores locais, está irremediavelmente entrelaçada à complexidade do contex to em que se deram os acontecimentos vividos, uma vez que, na produção do trabalho realizado por tais profissionais, esteve implicada e delimitada a condição de sua produção.

\section{PEDAGOGUES AND THE TEACHING / LEARNING: IMPACT AND CHALLENGES IN MANAGEMENT SCHOOL}

ABSTRACT: This paper aims at understanding the challenges involved in teaching and learning in the context of school management programs to support learning. From the contributions of Charlot (2000), Lahire (1997), Arroyo (2000), Bahia (2012) and Sawaia (2002) on the theme of learning / not learning at school we built a semistructured interview guide to meet the objective suggested. The research, which is characterized by a qualitative, descriptive and interpretive study, as Cervo, (2007), was conducted in five schools in the city of Londrina - Pr and involved eight pedagogues. Among the results we emphasize: the opening of the learning support room is considered very significant for the development of students who do not have the expected performance. Such students are usually identified as having learning difficulties, however, sometimes the unsatisfactory performance is diagnosed as resulting from teaching problems, insufficient training of teachers for the current reality, little involvement of families and lack of resources. Setting up the programme causes changes in the school routine: rearrangement of space and new materials and also establishes the need for new ways of working among those involved without having suitable conditions to perform them.

KEYWORDS: Teaching and learning. Learning support room. Pedagogues. Significations. 


\section{REFERÊNCIAS}

AQUINO, J. G. Erro e fracasso na escola: alternativas teóricas e práticas. 2.ed. São Paulo: Summus, 1997.

ARROYO, M. Ofício de mestre: imagens e auto-imagens. Petrópolis, RJ: Vozes, 2000.

BAHIA, N. P. O fracasso escolar e a reclusão dos excluídos. São Paulo: Alexa Cultural, 2012.

CERVO, A. L. Metodologia científica: ensaios. São Paulo: Saraiva, 2007.

CHARLOT, B. Professores, alunos, escola, saber: relações atravessadas pela contradição. Cadernos de Educação, Pelotas, n.39, p.15-35, mai./ago. 2011.

2000.

Da relação com o saber: elementos para uma teoria. Porto Alegre: Artmed,

CLOT, Y. A função psicológica do trabalho. Petrópolis, RJ: Vozes, 2007.

HÉBRARD, J. O objetivo da escola é a cultura, não a vida mesma. Revista Presença Pedagógica, Belo Horizonte, v.6, n.33, p.5-17, mai./jun. 2000.

LAHIRE, B. Sucesso escolar nos meios populares: as razões do improvável. São Paulo: Ática, 1997.

PARANÁ. Critérios para a abertura da demanda de horas-aula, do suprimento e das atribuições dos profissionais das Salas de Apoio à Aprendizagem do Ensino Fundamental, da Rede Pública Estadual de Educação. Instrução n. 007/2011 SUED/SEED. Curitiba, 4 jul. 2011. Disponível em:

<http://www.educacao.pr.gov.br/arquivos/File/instrucoes/instrucao0072011.pdf>. Acesso em: 2 mar. 2015.

PATTO, M. H. S. A produção do fracasso escolar. São Paulo: T. A. Queiroz, 1990.

SÃO PAULO. Regime de Progressão Continuada. Deliberação CEE/SP 9/97. São Paulo, 30 jul. 1997. Disponível em:

$<$ http://www.sieeesp.org.br/index.php?acao=51\&codigo=454>. Acesso em: $11 \mathrm{fev}$. 2015.

Programa Classes de Aceleração. Deliberação CEE/SP 170/96. São Paulo, 24 abr. 1996. Disponível em:

<http://siau.edunet.sp.gov.br/ItemLise/arquivos/13_1996.htm?Time=02/03/2015\%2011: 17:36>. Acesso em 2 mar. 2015.

Normas atinentes ao ciclo básico. Resolução SE n. 13/84. 1984. Disponível

em:

<http://siau.edunet.sp.gov.br/ItemLise/arquivos/notas/13_1984.htm?Time=8/29/2009\% 209:55:08\%20AM> Acesso em 11 fev. 2015. 
SAWAIA, S. M. Novas perspectivas sobre o sucesso e o fracasso escolar. In:

OLIVEIRA, M. K.; SOUZA, D. T. R.; REGO, T. R. (Org.). Psicologia, Educação e as

Temáticas da Vida Contemporânea. São Paulo: Moderna, 2002. p.197-213.

SCHIEMANN, A. L.; NUNES, T.; CARRAHER, D. Na vida dez, na escola zero.

16.ed. São Paulo: Cortez, 2012.

SCHWARTZ, Y. Trabalho e uso de si. Revista Proposições, Campinas, v.11, n.2(32), jul. 2000. Disponível em:

<http://www.proposicoes.fe.unicamp.br/proposicoes/textos/32-artigos-schwartzy.pdf>. Acesso em: 15 fev. 2015.

SOARES, M. Alfabetização e letramento. São Paulo: Contexto, 2011. 